Disponible en ligne sur

SciVerse ScienceDirect

www.sciencedirect.com
Elsevier Masson France

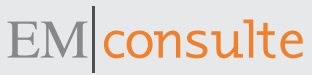

www.em-consulte.com

ORIGINAL ARTICLE

\title{
Effect of high intensity interval training on elite athletes' antioxidant status
}

\section{Effet de l'entraînement par intervalles à haute intensité sur le statut antioxydant des athlètes de haut niveau}

\section{A. Faruk Ugras}

Bilkent University, Department of Physical Education and Sports, 06800 Ankara, Turkey

Received 28 July 2010; accepted 25 April 2012

Available online 7 June 2012

\section{KEYWORDS}

Athletes;

Interval training;

SOD;

CAT;

GPX;

MDA

\begin{abstract}
Summary
Objective. - The effects of high intensity interval exercises on antioxidant defense system are not clear. Since there is an evident lack of studies focused on oxidative stress experienced following combat sports and high intensity interval training, we investigated oxidative stress markers (malondialdehyde [MDA], catalase [CAT], glutathione peroxidase [GPX], superoxide dismutase [SOD]) by completing high intensity interval training program (HIITP) and following International Muay Thai Championship (IMTC).

Methods. - The study was carried out on 21 elite players (15 males and six females) who had regular exercising and training habits. The participants were subjected to a daily 3-hour HIITP during brief training camp (10-day) before IMTC. They were instructed to maintain their normal dietary practices throughout the camp and during the study to take no antioxidant containing vitamin tablets.

Results. - There was a significant increase in MDA levels and significant decrease in CAT activities of players $(P<0.05)$. The differences in SOD and GPX activities were not significant.

Conclusion. - These results suggested that high intensity interval training and competition could affect the oxidative status of Muay Thai (MT) athletes.

(c) 2012 Elsevier Masson SAS. All rights reserved.
\end{abstract}

\section{Résumé}

Objectif. - Les effets des exercices de haute intensité par intervalle sur le système de défense antioxydant ne sont pas clairs. Comme il existe un manque évident d'études portant sur le stress oxydatif survenu lors des sports de combat et d'entraînements par intervalles à haute intensité, nous avons étudié les marqueurs de stress oxydatif (malondialdehyde [MDA], catalase [CAT], glutathione peroxidase [GPX], superoxide dismutase [SOD]) en complétant les programmes d'entraînements par intervalle de haute intensité (EPI) et à la suite du Championnat international de Muay Thaï (IMTC).

E-mail address: ugras@bilkent.edu.tr

0765-1597/\$ - see front matter @ 2012 Elsevier Masson SAS. All rights reserved. 
GPX ;

MDA

Méthodes. - L'étude a été réalisée sur 21 athlètes de haut niveau ( 15 hommes et six femmes) qui avaient l'habitude d'effectuer des exercices et des entraînements réguliers. Les participants ont été soumis à un programme d'entraînements par intervalle journaliers de trois heures (EPI) pendant des stages d'entraînement de courte durée (dix jours) avant le IMTC. Les athlètes avaient pour instruction de maintenir leurs habitudes alimentaires pendant toute la durée du stage d'entraînement et de ne prendre aucun comprimé de vitamines antioxydants durant l'étude.

Résultats. - Il y a eu une augmentation significative des niveaux de MDA et une diminution significative des activités de CAT des athlètes $(P<0,05)$. Les différences dans les activités de SOD et de GPX ne sont pas significatives.

Conclusion. - Ce résultat suggère que l'entraînement par intervalle de haute intensité et la compétition peut affecter le statut oxydatif des athlètes de Muay Thaï (MT).

(c) 2012 Elsevier Masson SAS. Tous droits réservés.

\section{Introduction}

Reactive oxygen species (ROS) are generated by regular metabolic process in vivo and can initiate a cascade of free-radical formation and damage to macromolecules [1]. Oxidative stress is an inevitable consequence of aerobic life, and there is growing evidence that the endogenous generation of ROS plays a major role in aging and many pathological conditions [2]. In resting state the body is equipped with both non-enzymatic and enzymatic antioxidant defense system to scavenge the potentially harmful effects of ROS $[3,4]$. This system includes antioxidant enzymes such as glutathione peroxidase (GPX), catalase (CAT), and superoxide dismutase (SOD), and non-enzymatic molecules including vitamin $\mathrm{E}$, vitamin $\mathrm{C}$, vitamin A precursor, thiol-containing compounds e.g. glutathione (GSH). These antioxidant defense systems preserve homeostasis for normal cell functions at rest and under normal physiological conditions. However, during strenuous exercise, pathogenic processes and aging, ROS production may overwhelm antioxidant defense capacity causing cell and tissue damage $[5,6]$. As consequences the bilayer lipid membrane of the cells, proteins, and even DNA material may suffer oxidative damage [7].

Many athletes involved in different intense physical activities during physical training and sportive events, which are performed in uncontrolled setting and often possess components of both an aerobic and anaerobic nature [8]. Excessive training can produce oxidative stress and antioxidant elements of organisms were affected with this challenge [9]. Few studies have investigated oxidative stress in response to both aerobic and anaerobic exercise bouts $[10,11]$ especially oxidative stress, which is experienced following sporting competitions [8]. Higher resting plasma MDA levels were reported in sprint-trained athletes compared with control subjects. It was reported that plasma MDA levels following an extreme endurance event in elite athlete increased [12]. Several studies have also reported that acute, high intensity physical exercise induces oxidative stress [13-16].

Muay Thai (MT) is one of the combat sports and field observation has shown that it is intermittent in nature and similar to that of karate, taekwondo, boxing and wrestling. MT training consists of both strenuous and exhaustive exercises [17]. MT involves a style of boxing where competitors try to win bouts and international level amateur bouts involve four 2-minute rounds with 1-minute rest periods [18]. Sparring is very intermittent in nature, divided into periods of very high intensive activity (when attacking or blocking) and low intensive activity when the athlete is preparing for an attack or just moving around [19] from which athletes can receive short term recovery, as well as time to prepare for following attack. Thus, sparring performances principally rely on the immediate (ATP-PC) and short-term (Glycolysis) energy systems [17]. As the development of free radicals and scavenging of them are an important consideration for optimal performance, recovery, and health for players [20]. We aimed to investigate the oxidative status of MT athletes by completing high intensity interval training program (HIITP) and following International Muay Thai championship (IMTC).

\section{Methods}

\subsection{Subjects}

In this study, 15 males and six females MT national athletes were selected as the athletic subjects. The oxidative stress parameters of athletes before camp period were used as a control value for a proper comparison. Subjects had regular exercising and training habits for three times a week for 120 minutes at an elite level. Each athlete had at least 6 years of training experience. The exclusion criteria for study were drugs and medicines intake both, suffering from some illness and cigarette smoke. None of the athletes had to be excluded from the study. During camps, athletes went under some of the hematological tests as a normal procedure. The investigated period included the 10 days camp duration before the IMTC. Before the tests, the participants were given adequate information about the importance of the study and they signed a consenting document. All training sessions took place at the same time of day to control the circadian variation in performance. During the study, the subjects stayed in the same hotel and were provided with the same diet without any extra antioxidants or other nutritional supplements. The subjects showed $100 \%$ compliance with the exercise training program. The participants were instructed to refrain from eating or drinking immediately before the tests, and to refrain from smoking. They are also instructed not to participate in 
exercise 24 hours before each testing session. The protocol started one day before the beginning of the training period.

\subsection{Physiological measurements}

The body mass was measured using calibrated digital scales and height was measured using a portable stadiometer. The age of athletes were accurately recorded in years. Blood samples were taken from the participant three times; the first one prior to training, the second one after the training camp and the third one after the IMTC. We also analyzed the oxidative stress biomarkers at three different times: precamp, after camp and at the end of the IMTC. The training consisted of exercises to strengthen physical fitness through technical training and sparring practices. The HIITP applied to all athletes. The present HIITP was designed according to elite MT athletes' needs, after taking into consideration "the prerequisites in performance". The HIITP is a valuable method for improving both aerobic and anaerobic fitness. Training intensity was determined by use of maximal heart rate method [21].

The HIIT sessions lasted approximately 3 hours a day; $1 \frac{1}{2}$ hours in the morning, $1 \frac{1 / 2}{2}$ hours in the afternoon for the 3rd, 5th, 7th, and 9th day of camp. Athletes began daily practices both in the morning and afternoon sessions with a 20 minutes warm-up, that included running 5 minutes and was followed by calisthenics and stretching exercises. After warm-up, actual practice for HIITP approximately took 52 minutes in the morning and 48 minutes in the afternoon including a variety of repeated kicking and punching techniques and mini matches for 12 minutes only in the afternoon sessions. Twenty minutes cooling down exercises followed after both training programs. For the remaining days, athletes run with aerobic intensity and practice light MT exercises in the morning. In the afternoon all athletes take a complete rest. During training camp, along with the pre-competition training routine, mental and psychological skills (emotional control, arousal management i.e.) tailored towards the specific needs of athletes and they practiced at the simulated competition.

\subsection{Training session - High intensity interval training program (HIITP)}

\subsubsection{Morning practices}

Technical workout (TW): (front kick, side kick, roundhouse kick and punches- all done with alternating legs and arms):

- 20 minutes warm-up;

- 6 seconds work (95-100\% of $\mathrm{MaxVO}_{2}$ ), 18 seconds rest, 20 rpt, total of two sets of work, 5 minutes rest ${ }^{1}$ in between the set;

- 10 seconds work (95-100\% of $\mathrm{MaxVO}_{2}$ ), 30 seconds rest, 12 rpt, total of two sets of work, 5 minutes rest ${ }^{1}$ in between the set;

- 20 minutes cooling down exercises.

\footnotetext{
${ }^{1}$ Passive recovery refers to periods that do not involve any form of activity.
}

\subsubsection{Afternoon practices}

TW:

- 20 minutes warm-up;

- 30 seconds work (80-90\% of $\mathrm{MaxVO}_{2}$ ), 60 seconds rest, 4 rpt, total of two sets of work, 3 minutes rest ${ }^{2}$ in between the set;

- 60 seconds work (80-90\% of $\mathrm{MaxVO}_{2}$ ), 120 seconds rest, 2 rpt, total of two sets of work, 3 minutes rest ${ }^{2}$ in between the set;

- 2 minutes sparring, total of four sets of work, 1 minute rest in between the set;

- 20 minutes cooling down exercises.

\subsubsection{Training protocol}

Period: 10-day.

Training frequency: 2 times a day.

1st day: 1 st test.

2nd, 4th, 6th, 8th days: $1 / 2$ day aerobic running and low intensity MT technical/tactical activities \& $1 / 2$ day rest, $3 r d$, 5th, 7th, 9th days: HIITP.

10th day: 2 nd test.

Training hours: $10.00-11.30$ a.m. and 5.00-6.30 p.m.

Training type: Interval (every other day) and aerobic low intensity of running.

Training intensity: $95-100 \%$ of $\mathrm{MaxVO}_{2}$ (Morning) and 80-90\% of $\mathrm{MaxVO}_{2}$ (Afternoon).

Training period: approximately $1 \frac{1}{2}$ hour/session.

Blood Test: 1st, 10th days of the camp, and after the championship.

\subsection{Measurement of oxidative status}

Erythrocyte SOD, GPX, and malondialdehyde (MDA) were measured as previously described by Aydin et al. [23]. Erythrocyte CAT activity was measured in hemolysates as described by Aebi [24].

\subsection{Statistical analysis}

All statistical analyses were calculated by the SPSS statistical package. A paired $t$-test was used to determine the differences in physiological parameters between pre- and post-values. Data were expressed as mean values \pm standard deviation (SD) and standard error (SE). Differences between before and after exercises were reported as mean difference $\pm 95 \%$ confidence intervals. The statistical analysis was calculated with non-parametric test Wilcoxon Signed Ranks test for the oxidative stress parameters.

\section{Results}

Physical characteristics of the MT male and female athletes are presented in Table 1 . The body weight of male and female athletes did not changed during the championship.

\footnotetext{
${ }^{2}$ Active rest-low to moderate activity is effective immediately following sustained high intensity training or competition, particularly where the anaerobic glycolytic energy pathway has been substantially involved [22].
} 
Table 1 Physical characteristics of the Muay Thai (MT) male and female athletes.

\begin{tabular}{llll}
\hline Selected Physical Parameters & Before X1 & After X2 & Mean difference $\pm 95 \% \mathrm{Cl}$ \\
\hline Male $(n=15)$ & & & \\
$\quad$ Age $($ year $)$ & $20.93 \pm 2.43$ & & \\
Height $(\mathrm{cm})$ & $178.60 \pm 6.98(1.80)$ & $68.04 \pm 12.72(3.28)^{*}$ & \\
$\quad$ Body weight $(\mathrm{kg})$ & $68.71 \pm 13.02(3.36)$ & & \\
Female $(n=6)$ & $18.83 \pm 1.47$ & & \\
Age (year) & $170 \pm 1.79(0.73)$ & $56.86 \pm 7.59(3.09)^{*}$ & $0.41 \pm 0.09(0.04)$ \\
Height $(\mathrm{cm})$ & $57.28 \pm 7.58$ & & \\
Body weight $(\mathrm{kg})$ & & & \\
\hline
\end{tabular}

Values are the mean \pm SD $(S E)$. Before the camp training; after the camp training * $(P<0.01)$.

Table 2 The erythrocyte oxidative stress status of Muay Thai (MT) athletes.

\begin{tabular}{lllll}
\hline & SOD $(\mathrm{U} / \mathrm{ml})$ & CAT $(\mathrm{KU} / \mathrm{ml})$ & GPX $(\mathrm{U} / \mathrm{ml})$ & $\mathrm{MDA}(\mathrm{nmol} / \mathrm{ml})$ \\
\hline Pre-training & $343.62 \pm 168.38$ & $111.06 \pm 22.28$ & $11.45 \pm 3.12$ & $32.67 \pm 2.47$ \\
Post-training & $330.10 \pm 168.40$ & $109.30 \pm 17.12$ & $10.76 \pm 3.18$ & $45.52 \pm 4.01^{\mathrm{a}}$ \\
After the championship & $293.65 \pm 128.37$ & $87.07 \pm 13.69^{\mathrm{a}, \mathrm{b}}$ & $11.61 \pm 3.07$ & $49.80 \pm 2.29^{\mathrm{a}} \mathrm{b}$
\end{tabular}

SOD: superoxide dismutase; CAT: catalase; GPX: glutathione peroxidase; MDA: malondialdehyde. $n=21$ (six females, 15 males).

${ }^{a} p<0.05$ when compared with pre-training.

b $p<0.05$ when compared with post-training.
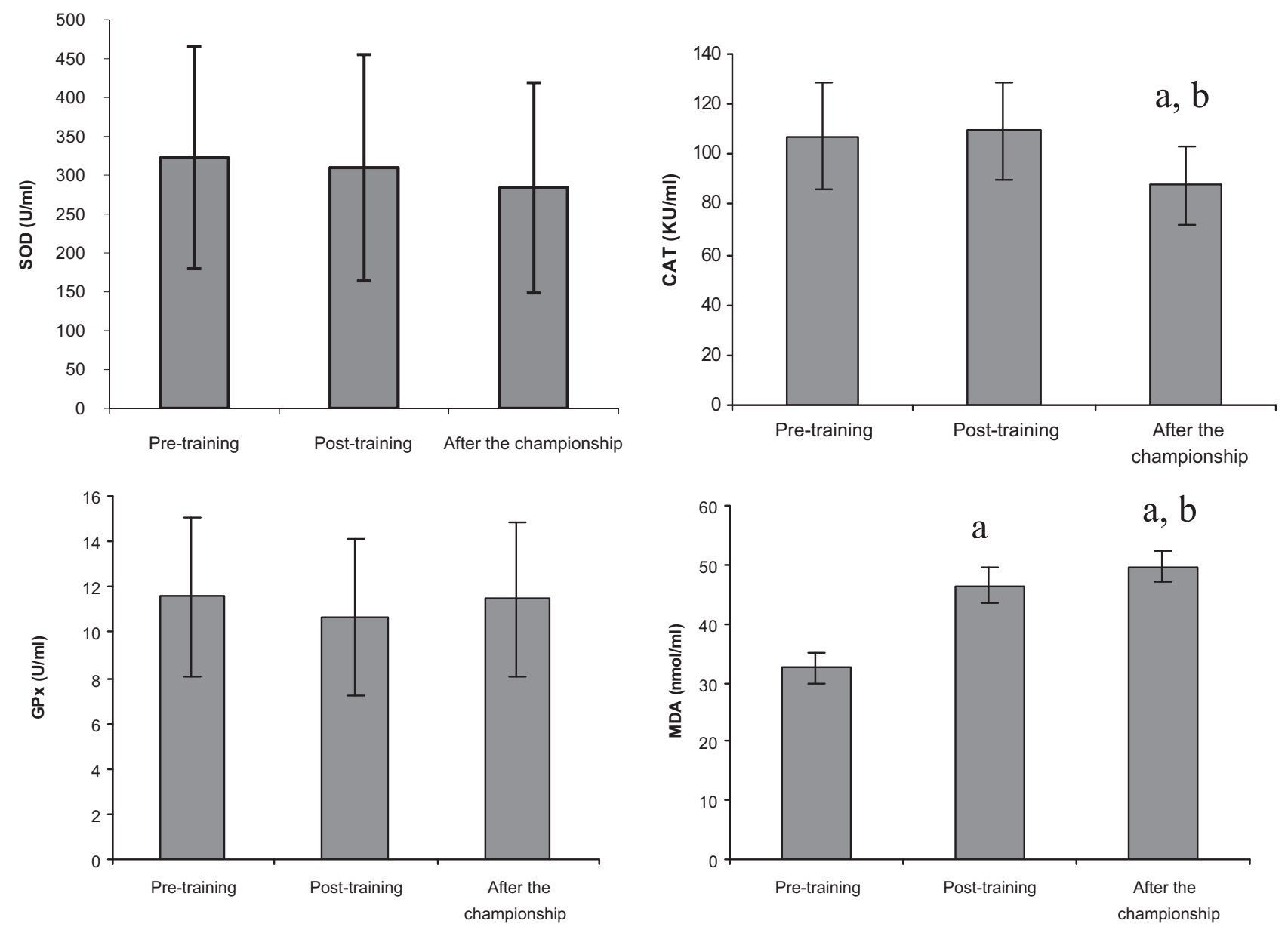

Figure 1 The oxidative stress status of male athletes. Three dependent groups were compared with non-parametric Wilcoxon Signed Ranks test. Values are expressed as mean \pm S.D. SOD: superoxide dismutase; CAT: catalase; GPX: glutathione peroxidase; MDA: malondialdehyde. $n=15$. a: $P<0.05$ when compared with pre-training; $\mathrm{b}: P<0.05$ when compared with post-training. 

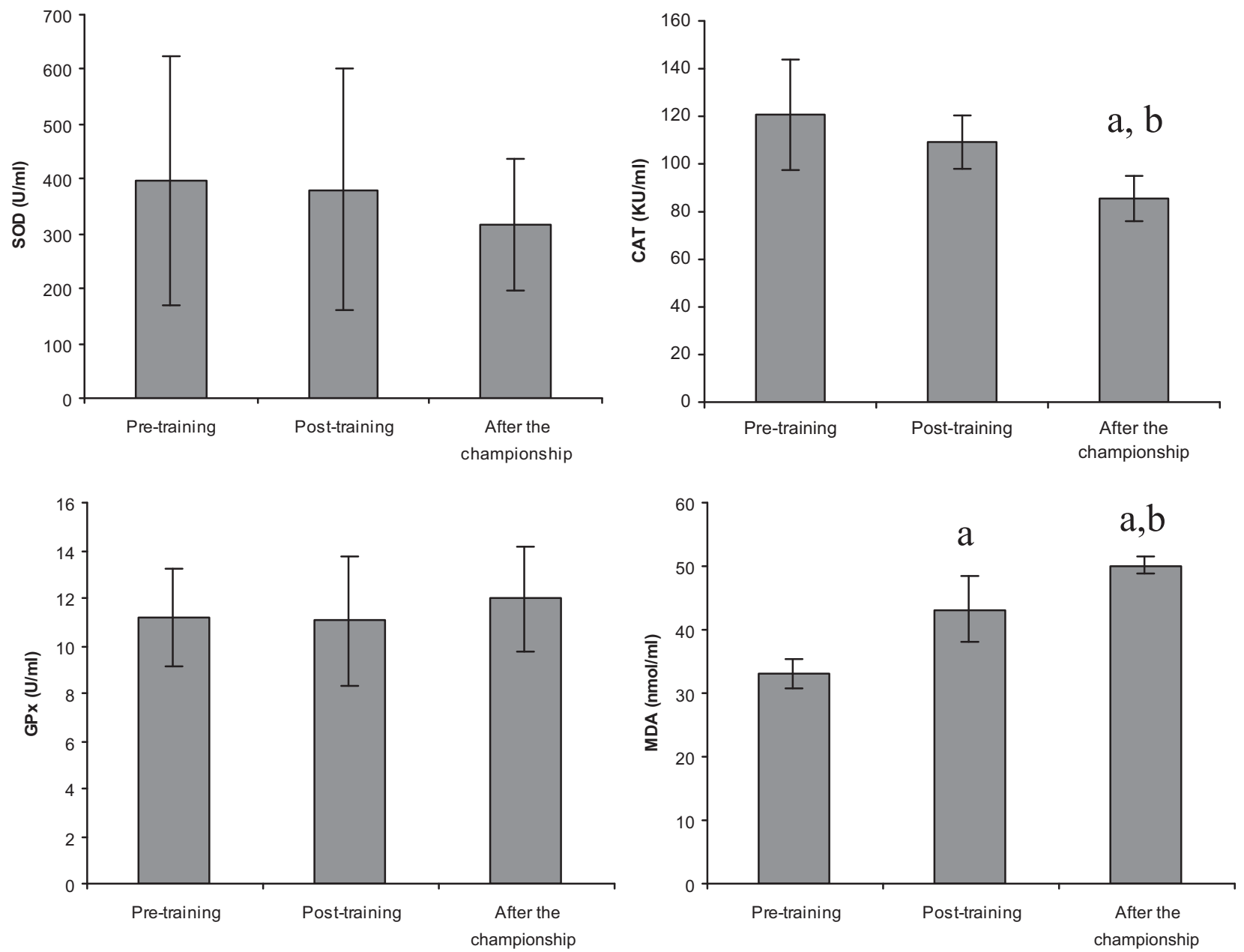

Figure 2 The oxidative stress status of female athletes. Three dependent groups were compared with non-parametric Wilcoxon Signed Ranks test. Values are expressed as mean \pm S.D. SOD: superoxide dismutase; CAT: catalase; GPX: glutathione peroxidase; MDA: malondialdehyde. $n=6$. a: $P<0.05$ when compared with pre-training; b: $P<0.05$ when compared with post-training.

Oxidative stress parameters were presented in Table 2. MDA levels increased post training and after the championship $(P<0.05)$, CAT activities decreased after the championship $(P<0.05)$. SOD activities decreased post training and after the championship, but these differences were not significant. GPX activities did not change. The oxidative stress status changed for both female and male athletes (Table 2, Figs. 1 and 2).

\section{Discussion}

Physical exercise is a complex biological activity challenging homeostasis at the cell, tissue, organ and whole body levels [25]. There are numerous reports that provide reasonable support to the notion that exercise increases the production of ROS [26]. Little is known, regarding the extent of oxidative stress when comparing aerobic and anaerobic exercise modes [10].

On the occurrence of exercise, stress is not fully clear. However, the principal factor responsible for oxidative damage during exercise is the increase in oxygen consumption [27], It appears that anaerobic types of exercise, which involves less oxygen circulation throughout the body than aerobic exercise is associated with an increased ROS generation level through other pathways [8,11] suggesting that oxygen consumption per se is not the major cause of exercise-induced oxidative damage [11].

Different types of exercise would have different effects on oxidative stress [11] which is defined as a situation in which an increased level of ROS generation overwhelms the antioxidant defense capacity, resulting in oxidative damage to lipids, proteins and DNA $[11,28]$.

A review of literature on changes in oxidative stress markers and physical parameters following the MT training and championship indicates a lack of information in this subject area. For this reason we investigated the oxidative status of athletes during competition season by completing HIIT program and following IMTC.

Field observation has shown that, MT activity is extremely dynamic in nature and during sparring athlete repeated explosive movements at a high intensity followed by sub-maximal work. Thus the primarily energy systems utilized are the anaerobic ATP-CP and lactic systems [17].

It was reported that the activities of antioxidant enzymes including SOD, CAT, and GSH peroxidase (GPX) increased with 
an acute bout of exercise in skeletal muscle, heart and liver [3].

SOD, CAT, GPX an MDA activities in response to exercise are variable. When we looked at our study, we observed that MDA levels increased in the period of post training and after the championship $(P<0.05)$, CAT activities decreased after the championship $(P<0.05)$. SOD activities decreased in the post-training period and after the championship, but these differences were not significant. GPX activities did not change in all samples. The oxidative stress status changed for both female and male athletes. It is concluded with these results that oxygen radicals were produced after strenuous physical training and some antioxidant enzyme activities were decreased.

When oxygen radicals were not scavenged properly by antioxidant enzymes they affected lipid molecules in cells and MDA levels were increased. These results supported our hypothesis. Zoppi et al. [7] arrived at the same conclusion in their study, suggesting that antioxidant supplementation had positive effects on antioxidant capacity of the players. Baker et al. [29] reported the increased MDA levels in high-intensity exercise and supported our results. Several studies reported that single bout of exercise increase blood levels of MDA $[4,14]$. Higher resting plasma MDA reported in sprint-trained athletes compared with control subjects. Elevated in plasma MDA following an extreme endurance event in elite athlete also reported [12]. Not all studies reported increases in MDA in response to physical effort. Miyazaki $\mathrm{H}$. et al. observed no change in erythrocyte MDA after a 12-week training program [14].

According to the Metin et al. [9] excessive training can produce oxidative stress and organism's antioxidant elements were stimulated with this challenge. This idea can be explained as an adaptive mechanism. In every condition it is clear that oxygen radicals are produced in the organisms during strenuous training periods. For this reason nutrition planning including antioxidant supplementation is considered as an important measure against the hazardous effects of free radicals.

SOD is one of the main antioxidant enzymes that degrade superoxide radicals [30] increase in SOD enzyme activity corresponds with enhanced resistance to oxidative stress. Groussard et al. found that SOD activity decreased after a single sprint anaerobic exercise [27]. Not all studies reported decrease in SOD in response to exercise. It has been reported that 8 -week moderate intensity of aerobic training did not elevate SOD activity. Furthermore, it has been revealed a decrease in SOD levels following an acute bout of exercise in skiers participating in a graded treadmill test to exhaustion and elevated erythrocyte SOD activity immediately post-exercise when the sprinters performed a sprint exercise [12].

CAT activity in response to exercise is variable. Following a bout of sub-maximal exercise a decrease in erythrocyte CAT activity reported in trained cyclists.

Furthermore, it has been reported that sprinters who performed a sprint-type exercise did not have altered erythrocyte CAT activity [12].

GPX activity is a key component of the glutathione homeostasis and its response to exercise is variable [28]. Higher in oxygen consumption during exercise activates the enzyme GPX to remove hydrogen peroxide. In response to an acute bout of high intensity exercise, elevated erythrocyte GPX activity has been found after a sprint exercise but no change when runners performed an endurance exercise [12].

The present study is the first to report improvements in oxidative status after short-term high intensity interval training and immediately after MT competition. We speculate that changes in these parameters might represent an increase in ROS after high intensity interval training.

In comparison with other investigators, we believe the present study provided the first direct analysis of effect of high intensity interval training on elite athletes' antioxidant status after training and competition.

The results of this study also suggest that a brief training camp, which the HIIT program is carried out appear to cause positive changes on physiological parameters due to some biological reasons linked with preparation for high performance and oxidative status of MT athletes. However, it was observed that oxidative damage increased. The recruitment of a limited number of special MT athletes was the limitation of our study. Further studies are needed whether similar adaptations are manifest after a couple of weeks of different type of interval training. After this kind of studies the nutrition component of elite athletes can be arranged against oxidative damage.

\section{Disclosure of interest}

The author declares that he has no conflicts of interest concerning this article.

\section{Acknowledgements}

The author would like to thank Huseyin G. Sonmez ${ }^{3}$ for technical assistance, Ayse Eken, Ph.D. ${ }^{4}$, Onur Erdem, Ph.D. ${ }^{4}$, Cemal Akay, Ph.D. ${ }^{4}$, Ahmet Sayal, Ph.D. ${ }^{4}$, Ahmet Aydin, Ph.D. ${ }^{5}$, and Mesut Akyol, Ph.D. ${ }^{6}$ for measuring oxidative stress parameters, and Julia Goggin ${ }^{7}$ for helping with proof reading.

\section{References}

[1] Forsberg L, de Faire U, Morgenstern R. Oxidative stress, human genetic variation, and disease. Arch Biochem Biophys 2001;389:84-93.

[2] Cooke M, Evans M, Dizdaroglu M, Lunec J. Oxidative DNA damage: mechanisms, mutation, and disease. FASEB J 2003;17:1195-214.

[3] Banarje AK, Mandal A, Chanda D, Chakraborti S. Oxidant, antioxidant and physical exercise. Mol Cell Biochem 2003;253:307-12.

\footnotetext{
3 Bilkent University, Department of Physical Education and Sport, 06800 Ankara, Turkey.

${ }^{4}$ Gülhane Military Medical Academy, Department of Toxicology, Etlik, 06010 Ankara, Turkey.

5 Yeditepe University, Faculty of Pharmacy, Department of Toxicology, Kayisdagi, 34755 Istanbul, Turkey.

${ }^{6}$ Gülhane Military Medical Academy, Department of Biostatistics, Etlik, 06010 Ankara, Turkey.

7 Bilkent University, Faculty Academic English Program, 06800 Ankara, Turkey.
} 
[4] Koska J, Blazicek P, Marko M, Grna JD, Kvetnansky R, Oigas $M$. Insulin, catecholamines, glucose and antioxidant enzymes in oxidative damage during different loads in healthy humans. Physiol Res 2000;49(Suppl. 19):S95-100.

[5] Ji LL. Free radicals and exercise: implication in health and fitness. J Exerc Sci Fitness 2003;1(1):15-22.

[6] Kanter M. Free radicals, exercise and antioxidant supplementation. Proc Nutr Soc 1988;57:9-13.

[7] Zoppi CC, Hohl R, Silva FC, Lazarim FL, Neto JMFA, Stancanneli $M$, et al. Vitamin $C$ and $E$ supplementation effects in professional soccer players under regular training. J Int Soc Sports Nutr 2006;3(2):37-44.

[8] Fisher-Wellman K, Bloomer RJ. Acute exercise and oxidative stress: a 30-year history. Dyn Med 2009;8(1):1-25.

[9] Metin G, Gumustas MK, Uslu E, Belce A, Kayserilioglu A. Effects of regular training on plasma thiols, malondialdehyde and carnitine concentrations in young soccer players. Chin J Physiol 2003;46(1):35-9.

[10] Bloomer RJ, Smith WA. Oxidative stress in response to aerobic and anaerobic power testing: Influence of exercise training and carnitine supplementation. Res Sports Med 2009;17:1-16.

[11] Shi M, Wang X, Yamanaka T, Ogita F, Nakatani K, Takeuchi T. Effects of anaerobic exercise and aerobic exercise on biomarkers of oxidative stress. Environ Health Prev Med 2007;12:202-8.

[12] Urso ML, Clarkson PM. Oxidative stress, exercise and antioxidant supplementation. Toxicology 2003;189:41-5.

[13] Belviranlı M, Gokbel H. Acute exercise induced oxidative stress and antioxidant changes. Eur J Gen Med 2006;3(3):126-31.

[14] Miyazaki H, Oh-ishi S, Ookawara T, Kizaki T, Toshinai K, Ha S, et al. Strenuous endurance training in humans reduces oxidative stress following exhausting exercise. Eur J Appl Physiol 2001;84:1-6.

[15] Pepe H, Balci SS, Revan S, Akalin PP, Kurtoglu F. Comparison of oxidative stress and antioxidant capacity before and after running exercises in both sexes. Gend Med 2009;6(4):587-95.

[16] Sureda A, Tauler P, Aguilo A, Cases N, Fuentespina E, Cordova $A$, et al. Relation between oxidative stress markers and antioxidant endogenous defenses during exhaustive exercise. Free Radic Res 2005;39(12):1317-24.

[17] McArdle WD, Katch FI, Katch VL. Nutrition for physical activity. Exercise training and functional capacity. In: McArdle WD,
Katch FI, Katch VL, editors. Essentials of exercise physiology. 1st ed Philadelphia: Lea and Febiger; 1994.

[18] Myers TD, Balmer NJ, Nevill AM, Nakeeb Y. Evidence of nationalistic bias in Muay Thai. J Sports Sci Med CSSI 2006:21-7.

[19] Nunan D. Development of a sports specific aerobic capacity test for karate - a pilot study. J Sports Sci Med CSSI 2006:47-53.

[20] Vollaard NB, Shearman JP, Cooper CE. Exercise-induced oxidative stress: myths, realities and physiological relevance. Sports Med 2005;35(12):1045-62.

[21] Fox EL, Bowers RW, Foss ML. Methods of physical training. In: Fox EL, Bowers RW, Foss ML, editors. The physiological basis for exercise and sport. 4th ed. New York: Sounders College Publishing; 1988.

[22] Clement D, Davidson R, Matheson GO, Newhouse I, Sawchuk L, Cox D, et al. Issues specific to women. In: Jackson R, Fitch $\mathrm{K}$, O'Brien M, editors. Sports medicine manual. 1st ed. Canadian Cataloguing in Publishing Data: Calgary; 1990.

[23] Aydin A, Hilmi O, Sayal A, Ozata M, Sahin G, Isimer A. Oxidative stress and nitric oxide related parameters in type II diabetes mellitus: effects of glycemic control. Clin Biochem 2001;34:65-70.

[24] Aebi H. Catalase in vitro. Methods Enzymol 1984;105:121-6.

[25] Ji LL, Radak Z, Goto S. Hormesis and exercise: how the cell copes with oxidative stress. Am J Pharmacol Toxicol 2008;3(1):44-58.

[26] Packer L, Cadenas E, Davies KJA. Free radicals and exercise: an introduction. Free Radic Biol Med 2008;44:123-5.

[27] Groussard C, Rannou-Bekono F, Machefer G, Chevanne M, Vincent $S$, Sergent $O$, et al. Changes in blood lipid peroxidation markers and antioxidants after a single sprint anaerobic exercise. Eur J Appl Physiol 2003;89:14-20.

[28] Kinnunen S, Atalay M, Hyypa S, Lehmuskero A, Hanninen O, Oksala N. Effects of prolonged exercise on oxidative stress and antioxidant defense in endurance horse. J Sports Sci Med 2000;4:415-21.

[29] Baker JS, Bailey DM, Hullin D, Young I, Davies B. Metabolic implications of resistive force selection for oxidative stress and markers of muscle damage during 30 s of high-intensity exercise. Eur J Appl Physiol 2004;92(3):321-7.

[30] Qiao D, Hou L, Liu X. Influence of intermittent anaerobic exercise on Mouse physical endurance and antioxidant components. Br J Sports Med 2006;40:214-8. 